\title{
METODOLOGIAS ATIVAS NO ENSINO MÉDIO INTEGRADO SOB A PERSPECTIVA DA EDUCAÇÃO INTEGRAL
}

\author{
ACTIVE METHODOLOGIES IN INTEGRATED HIGH SCHOOL UNDER THE PERSPECTIVE OF \\ INTEGRAL EDUCATION
}
METODOLOGÍAS ACTIVAS EN LA ESCUELA SECUNDARIA INTEGRADA BAJO LA PERSPECTIVA DE LA EDUCACIÓN INTEGRAL

\author{
Heidy Nunes de Ávila \\ Mestranda do Programa de Pós-Graduação Educação Profissional e Tecnológica (ProfEPT) - Instituto \\ Federal de Minas Gerais (IFMG) - Campus Ouro Branco. \\ E-mail: heidynunes2015@gmail.com. \\ Orcid: 31 99268-2507
}

\author{
Gustavo Pereira Pessoa \\ Doutor em Educação pela Pontifícia Universidade Católica de Minas Gerais (PUC-Minas).Professor do \\ Instituto Federal de Minas Gerais (IFMG) - Ibirité/MG - Brasil. \\ E-mail: gustavo.pessoa@ifmg.edu.br. \\ Orcid: 0000-0002-1379-1986
}

\begin{abstract}
RESUMO
Este artigo relata resultados de pesquisa empírica realizada com professores do Ensino Médio Integrado dos Institutos Federais de Educação, Ciência e Tecnologia de Minas Gerais. Objetivou-se investigar as concepções, práticas e conhecimentos dos participantes acerca de metodologias ativas e formação humana integral. Na coleta de dados foi utilizado questionário composto por questões objetivas e subjetivas; os dados obtidos foram analisados qualitativamente e organizados pelas seguintes categorias: formação e experiência profissional; concepção sobre ensino e aprendizagem e práticas educativas; conhecimento sobre metodologias ativas e formação humana integral. A pesquisa mostrou que, embora os docentes possuam concepções e conhecimentos favoráveis à utilização de metodologias ativas, a prática docente ainda se mantém fortemente vinculada a visões e métodos tradicionais. Identificou-se, ainda, diante de desafios apontados pelos docentes, a necessidade de maior aprofundamento nas questões acerca da integração do Ensino Médio e da Educação Integral.
\end{abstract}

Palavras-chave: Metodologias ativas. Educação integral. Ensino médio integrado.

\section{ABSTRACT}

This article reports the results of an empirical research carried out with Integrated High School teachers from the Federal Institutes of Education, Science and Technology of Minas Gerais. The objective was to investigate the participants' conceptions, practices and knowledge about active methodologies and integral human development formation. In the data collection, a questionnaire composed of objective and subjective questions was used; the data obtained were analyzed qualitatively and organized into the following categories: training and professional experience; conception about teaching and learning and educational practices; knowledge of active methodologies and comprehensive human training. The research showed that, although the teachers have conceptions and knowledge favorable to the use of active methodologies, the teaching practice still remains strongly linked to traditional views and methods. It was also identified, in the face of challenges pointed out by the teachers, the need for greater depth in the questions about the integration of High School and Integral Education. 
Keywords: Active methodologies. Integral education. Integrated High School.

\section{RESUMEN}

Este artículo informa los resultados de la investigación empírica realizada con profesores de la escuela secundaria integrada de los Institutos Federales de Educación, Ciencia y Tecnología de Minas Gerais. El objetivo fue investigar las concepciones, prácticas y conocimientos de los participantes sobre metodologías activas y formación humana integral. En la recolección de datos, se utilizó un cuestionario compuesto de preguntas objetivas y subjetivas; los datos obtenidos se analizaron cualitativamente y se organizaron en las siguientes categorías: formación y experiencia profesional; concepción sobre la enseñanza y el aprendizaje y las prácticas educativas; conocimiento de metodologías activas y formación humana integral. La investigación mostró que, aunque los profesores tienen concepciones y conocimientos favorables para el uso de metodologías activas, la práctica docente sigue estando fuertemente vinculada a los puntos de vista y métodos tradicionales. También se identificó, ante los desafíos señalados por los docentes, la necesidad de mayor profundidad en cuestiones relativas a la integración de la Educación Secundaria y la Educación Integral.

Palabras-clave: Metodologías activas. Educación integral. Escuela secundaria integrada.

\section{INTRODUÇÃO}

As grandes transformações políticas, econômicas e culturais ocorridas nas últimas décadas têm impactado a forma como nos relacionamos uns com os outros, com o mundo do trabalho e com a escola. Já há algum tempo, a expansão da Internet e das tecnologias digitais de informação e comunicação (TDIC) tem provocado incontestáveis mudanças nas formas de acesso e disseminação das informações. Diante desse cenário, é possível inferir que as atuais demandas sociais exigem do professor uma postura diferenciada, embora na contramão do contexto descrito —, a tradicional pedagogia da transmissão permanece hegemônica nos sistemas de ensino, de acordo com Christensen, Horn e Johnson (2009).

Araújo e Frigotto (2015, p. 62) destacam que a proposta de Ensino Médio Integrado (EMI), contexto desta pesquisa, vai contra a visão dualista de ensino, que separa a educação básica da profissional e, ainda, contra as perspectivas reducionistas de ensino, que proporcionam uma educação instrumental e conformada para a classe trabalhadora e uma educação criativa para a classe dominante, com ênfase na autonomia intelectual e política. Assim como Frigotto (2012), acredita-se que o Ensino Médio na perspectiva da Educação Integral deve proporcionar a formação de indivíduos críticos e capazes de atuar na realidade, com autonomia para transformá-la.

Para Ramos (2012), além da redefinição do marco curricular para o Ensino Médio Integrado, é necessária a redefinição dos processos de ensino que devem estar articulados à realidade do sujeito que aprende pela proposição de desafios, problemas e projetos, 
desencadeando ações resolutivas por parte do aluno. Buscando contribuir para a superação dessas lacunas, esta pesquisa possuiu como tema a proposição de metodologias ativas de ensino-aprendizagem no Ensino Médio Integrado à Educação Profissional, sob a perspectiva da Educação Integral. Acredita-se que o conhecimento desta metodologia, e das práticas pedagógicas por ela propostas, possa contribuir para algum avanço em direção à formação integral que se deseja para essa modalidade de ensino, já que suas técnicas favorecem o trabalho interdisciplinar, contextualizado e a articulação entre teoria e prática para o desenvolvimento de sujeitos críticos, participativos e autônomos.

\section{Discussão teórica}

\section{Fundamentação Teórica}

No século XX, importantes transformações econômicas, políticas e sociais que ocorreram no mundo, repercutiram no Brasil com um conjunto de ideias que pregavam a renovação dos métodos tradicionais e propunham uma pedagogia não diretiva, entre elas, a Escola Nova ou Escola Ativa, inspirada nos ideiais educacionais de John Dewey (18591952). Segundo Cunha (2007), o aprendizado na concepção deweyana ocorria naturalmente através das experiências acumuladas por meio da interação social, portanto, a educação deveria ser a reconstrução da experiência para favorecer o estabelecimento da autonomia do educando.

A Escola Ativa está alicerçada na teoria da aprendizagem sociointeracionista de Vygotsky que deslocou o foco, anteriormente centrado ou no sujeito (aluno) ou no conteúdo, para a mediação a partir da interação. Essa teoria se traduz na pedagogia construtivista em contraposição à pedagogia diretiva, ou tradicional, na qual o professor ocupava o papel central de transmissor de conhecimentos.

No Brasil, na mesma linha das perspectivas construtivistas de aprendizagem e dos ideais educacionais de John Dewey, destacam-se as concepções de Paulo Freire (19211997), educador que propunha o diálogo e participação mais ativa e questionadora do aluno, na promoção da autonomia como perspectiva para a transformação da sociedade. Paulo Freire também foi um crítico do formato da educação tradicional baseada em aulas expositivas, que denominou de educação bancária. De acordo com Freire (1996), neste 
formato de educação os alunos se tornam uma espécie de depósito de conteúdos fornecidos pelo professor, cabendo-lhes arquivar passivamente tudo o que fora depositado. A concepção freireana de educação está a serviço da autonomia e contribui, por meio do diálogo e da conscientização, para a formação de educandos sujeitos do seu próprio desenvolvimento e capazes de atuar de forma crítica na sociedade.

\section{Metodologias ativas e a Tecnologia Digital da Informação e Comunicação (TDIC)}

Metodologias ativas são práticas pedagógicas cujos alicerces epistemológicos são alternativos à forma de tradicional de ensino, fundamentada no paradigma da instrução. Esse paradigma pedagógico surgiu do ideal da razão iluminista e tem orientado as práticas pedagógicas desde o século XIX. Nele, o professor ocupa a centralidade do processo educativo como detentor dos saberes acumulados pela humanidade e responsável pela sua transmissão/reprodução. De acordo do Noffs e Santos (2019), a forma tradicional de ensino valoriza a ação docente como um ato prescritivo e, consequentemente, os discentes se relacionam com o saber de forma instrumental e passiva. Tal valorização da ação de ensinar, muitas vezes sem levar em conta o processo de aprendizagem, culmina em procedimentos didáticos sob a perspectiva comportamentalista.

O conceito de metodologias ativas, por sua vez, desenvolve-se a partir de perspectivas cognitivoconstrutivistas. No trabalho com metodologias ativas, ocorre o deslocamento da centralidade do processo educativo do professor para o aluno (em sua relação com o saber) como protagonista no processo de ensino-aprendizagem e responsável por contribuir de forma colaborativa para a construção do conhecimento. $\mathrm{O}$ professor passa a desempenhar o papel de tutor enquanto o aluno participa de forma mais efetiva e reflexiva do processo de aprendizagem, o que contribui para o desenvolvimento da autonomia.

Segundo Becker (2008), é importante conhecer as concepções epistemológicas que fundamentam as concepções de aprendizagem já que estas, por sua vez, determinam as práticas pedagógicas dos docentes. Para o autor, o professor ensina de acordo com seu conceito de aprendizagem e não consegue, por mais que tente, exercer uma prática diferente, a menos que realize "um esforço no sentido da crítica epistemológica e, por consequência, de mudança profunda na concepção de aprendizagem”. (BECKER, 2008, p. 
Para Christensen, Horn e Johnson (2009, p. 17), a aprendizagem "centrada no aluno, abre portas para que eles aprendam de acordo com modalidades que se adaptem aos tipos de inteligência, nos lugares e nos ritmos preferidos por eles". Os autores propõem que a inovação na educação se dê por meio da tecnologia associada a novos métodos de ensino e de avaliação, para superar o modelo no qual o professor ensina de uma forma igual para alunos heterogêneos.

Para Moran (2015, p. 16), métodos tradicionais de ensino faziam sentido quando o acesso à informação não era fácil como é hoje. Com a Internet e a divulgação aberta de informações, existem muitos caminhos para se aprender (seja individualmente ou em grupo) que questionam a rigidez dos projetos pedagógicos da instituição formal de ensino. Segundo Teixeira (2016, p. 145):

\begin{abstract}
As TDIC têm um caráter modernizador e fomentador de um novo jeito de "fazer" educação e entender o uso desses recursos pode desencadear uma ação potencializadora ao ponto de tornar a educação um processo ainda mais democrático e transformador.
\end{abstract}

Entende-se, entretanto, que as tecnologias podem ser facilitadoras de um processo de ensino-aprendizagem emancipatório, porém, não resolvem todos os problemas enfrentados no dia a dia das escolas. Além das práticas pedagógicas, questões referentes à infraestrutura e inserção curricular através do Projeto Político Pedagógico (PPP) da instituição são pontos cruciais para que as tecnologias possam contribuir para a transformação do ensino. Christensen, Horn e Johnson (2009, p. 53) afirmam que "os computadores não serviram quase nada para a concretização do promissor caminho de consolidar a motivação intrínseca dos estudantes, por intermédio de um ensino centrado no aluno".

\title{
Educação Integral e Ensino Médio Integrado
}

A educação no Brasil é marcada pela dualidade estrutural que, em linhas gerais, diz respeito à destinação intencional da educação propedêutica, voltada para a continuação dos estudos em nível superior, reservado às classes dominantes e da educação profissional para a classe trabalhadora. Para Grabowski e Kuenzer (2016, p. 24), “é a partir do ensino médio, e em especial na educação profissional, que essa categoria apresenta maior poder explicativo". De acordo com Moura, Lima Filho e Silva (2015) a proposta que busca superar a referida dualidade tem origem nas formulações sobre educação omnilateral ou integral 
de Marx, e na escola unitária de Gramsci, da qual nasce o conceito da formação humana integral, defendida pelos educadores brasileiros. As conceituações sobre formação humana integral englobam o princípio educativo do trabalho e propõem que a educação deve garantir o desenvolvimento dos sujeitos em todas as suas dimensões (intelectual, social, física e cultural), a fim de superar a referida dualidade educacional.

O ensino médio é a etapa final da educação básica brasileira e o Ensino Médio Integrado é uma modalidade que se caracteriza pela integração entre a educação técnica de nível médio e o ensino médio de caráter geral. Entende-se que esta modalidade de ensino seja a que melhor represente a busca pela articulação entre educação e trabalho, o que a caracteriza como a proposta mais promissora na direção da formação humana integral pretendida. Segundo Moura, Lima Filho e Silva (2015, p. 1072), ensino médio - que garanta uma base unitária de formação geral para todos, fundamentada na concepção de formação humana integral, tendo como eixo estrutural o trabalho, a ciência, a tecnologia e a cultura - integrado ao ensino técnico, é condição necessária para realizar a travessia para uma nova realidade. Araújo e Frigotto (2015, p. 66) defendem que, apesar das dificuldades, a proposta de ensino integrado não deve ser abandonada, ja que representa um projeto comprometido com a transformação social.

\section{Metodologia}

Após a revisão teórica, procedeu-se à pesquisa empírica com a coleta de dados realizada por meio do questionário sobre conhecimentos e práticas docentes contendo questões objetivas e subjetivas. De acordo com os objetivos propostos, buscou-se nesta fase levantar o perfil, as concepções e práticas dos professores atuantes no Ensino Médio Integrado nos Institutos Federais de Educação, Ciência e Tecnologia de Minas Gerais. A amostra foi aleatória; o instrumento de coleta de dados foi enviado a vários indivíduos que atendiam aos critérios dispostos no estudo e, a partir daí, os sujeitos espontaneamente decidiram sobre a sua participação.

O formulário foi criado na aplicação on-line Google Forms e encaminhado eletronicamente utilizando listagem de e-mails obtida junto à instituição. Foi realizado teste-piloto com 03 respondentes a fim de avaliar a assertividade da interface do questionário com o usuário, o tempo médio necessário para a resposta e a forma de apresentação dos dados pela plataforma. Após receber as respostas deste teste inicial, o 
qual contribuiu para a melhoria do instrumento, os dados destes 3 respondentes foram eliminados e o questionário foi encaminhado aos docentes; receberam-se um montante final de 50 respostas.

Os dados obtidos foram analisados qualitativamente e organizados pelas seguintes categorias: formação e experiência profissional; concepção sobre ensino e aprendizagem e práticas educativas; conhecimento sobre metodologias ativas e formação humana integral. À medida que os dados iam sendo analisados, foram surgindo novas subcategorias, sobretudo na análise das respostas às questões subjetivas. As respostas das questões objetivas foram ilustradas através de gráficos e tabelas para melhor especificação do perfil dos participantes. É importante esclarecer que a coleta de dados foi precedida da autorização pelo Comitê de Ética em Pesquisa do Centro Universitário UNA/MG (Parecer 3.526.732) e sua publicação autorizada pelos participantes, resguardado o anonimato.

\section{Resultados e discussões}

A primeira parte do questionário teve por objetivo identificar o perfil dos participantes por meio de dados pessoais e relativamente à sua formação e experiência profissional. Em relação à abrangência da amostra, obteve-se a partir de uma mobilização espontânea e aleatória a participação de docentes de 13 dos 19 campi do IFMG (68\%) totalizando 50 respostas.

O levantamento das concepções docentes sobre "ensino" e "aprendizagem" foi feito por meio de questões curtas que solicitavam aos participantes citarem 3 palavras ou expressões que lhes vinham à cabeça quando pensavam nestes conceitos. O mesmo formato de questões foi utilizado para identificar os conhecimentos dos participantes sobre "metodologias ativas" e "formação humana integral”, conforme demonstrado nas próximas análises.

A partir do estudo dos aspectos significativos do conteúdo, definiram-se para as concepções docentes sobre "ensino" e "aprendizagem" as categorias "tradicionais" e "ativas e dialógicas". A definição de tais categorias se deu por serem válidas em face dos objetivos deste estudo. Foi possível notar nesta parte da análise dos dados que as respostas da maioria dos docentes se encaixaram na categoria "ativas e dialógicas"; pôdese observar também que muitas respostas retrataram concepções tradicionais de ensino- 
aprendizagem. Após essa sondagem inicial partiu-se para indagações sobre a prática docente.

As questões referentes às práticas docentes solicitavam que os participantes assinalassem com que frequência adotavam determinada prática e atitude. Além destas, algumas perguntas buscaram identificar o grau de concordância dos participantes em relação às suas próprias práticas e a fatores a elas relacionados. De acordo com Becker (2008, p. 55), "o professor ensina a partir de sua concepção de aprendizagem; mesmo que essa ideia não seja assumida no plano da consciência", portanto "[...] um professor não poderá exercer uma pedagogia e uma didática inspiradas no construtivismo se continuar preso às concepções epistemológicas, empiristas ou aprioristas". Buscou-se, portanto identificar com que frequência os professores costumam adotar algumas práticas e atitudes a fim de verificar se estas condizem com as concepções anteriormente analisadas.

Os resultados das atitudes e práticas docentes estão apresentados nas Tabelas 1, 2 e 3. Na tabela 1 está identificada a frequência das atitudes adotadas pelos participantes em suas práticas. Na primeira parte da tabela estão transcritas as atitudes contidas nas perguntas e, na sequência, o número de resposta por frequência escolhida pelo participante (sempre, quase sempre, às vezes, nunca e quase nunca). Considerou-se, para esta análise, as atitudes adotadas "sempre ou quase sempre" como atitudes adotadas com ALTA frequência, e as atitudes adotadas "nunca ou quase nunca" como atitudes adotadas com BAIXA frequência e, por fim, as atitudes adotadas "às vezes" como frequência MEDIA. As duas últimas colunas da tabela apresentam o total da amostra e os percentuais de indivíduos que afirmaram agir com a frequência ALTA (somatória das respostas sempre e quase sempre) em relação ao total da amostra (50). O foco de análise concentrou-se na frequência ALTA para identificar quais são as atitudes e práticas mais habituais dos professores.

Tabela 1 - Frequência por atitude dos participantes

\begin{tabular}{|c|c|c|c|c|c|c|c|}
\hline \multirow[b]{3}{*}{ ATITUDE } & \multicolumn{5}{|c|}{ Quantidade de resposta x Frequência } & \multirow{3}{*}{$\begin{array}{c}\text { Total } \\
\text { da } \\
\text { amostra }\end{array}$} & \multirow{3}{*}{$\begin{array}{c}\text { Percentual } \\
\text { da } \\
\text { frequência } \\
\text { "ALTA" } \\
\text { sobre total } \\
\text { da amostra }\end{array}$} \\
\hline & \multicolumn{2}{|c|}{ ALTA } & \multirow{2}{*}{$\begin{array}{l}\text { MEDIA } \\
\text { Às } \\
\text { vezes }\end{array}$} & \multicolumn{2}{|c|}{ BAIXA } & & \\
\hline & Sempre & $\begin{array}{l}\text { Quase } \\
\text { sempre }\end{array}$ & & $\begin{array}{l}\text { Quase } \\
\text { nunca }\end{array}$ & Nunca & & \\
\hline
\end{tabular}




\begin{tabular}{|c|c|c|c|c|c|c|c|}
\hline $\begin{array}{l}\text { Busco identificar o } \\
\text { conhecimento } \\
\text { prévio do aluno } \\
\text { sobreo tema } \\
\text { abordado }\end{array}$ & 19 & 18 & 10 & 2 & 1 & \multirow{4}{*}{50} & $74 \%$ \\
\hline $\begin{array}{l}\text { Estou atento às } \\
\text { dificuldades de } \\
\text { cada aluno }\end{array}$ & 15 & 24 & 11 & & & & $78 \%$ \\
\hline $\begin{array}{l}\text { Estou disponível } \\
\text { para esclarecer } \\
\text { dúvidas }\end{array}$ & 42 & 6 & 2 & & & & $96 \%$ \\
\hline $\begin{array}{l}\text { Estudo sobre } \\
\text { processos de } \\
\text { aprendizado }\end{array}$ & 18 & 16 & 14 & 2 & & & $68 \%$ \\
\hline
\end{tabular}

Fonte: Elaborado pela autora com base em Virgem (2016)

Nota-se que a atitude adotada com frequência alta (sempre e quase sempre) pela maioria (96\%) dos professores é “estar disponível para esclarecer dúvidas”; uma atitude que, embora importante, denota uma concepção mais tradicionalista do processo de ensino, em que o professor transmite os conhecimentos e espera que alunos os absorvam, colocando-se à disposição para o esclarecimento de dúvidas, caso ocorram. Atitudes que denotam uma pedagogia mais construtivista e personalizada como "identificar o conhecimento prévio do aluno" e "estar atento às dificuldades de cada aluno" são adotadas com frequência alta por um percentual um pouco menor de professores.

As práticas docentes foram classificadas quanto aos "métodos de ensino e aprendizagem" e à "utilização de TDIC" conforme Tabelas 2 e 3. As perguntas solicitavam que os docentes assinalassem a frequência com que utilizam determinado recurso ou estratégia em suas práticas. A forma de organização dos dados para análise foi igual à utilizada para análise da tabela de atitudes.

Tabela 2 - Frequência por prática docente - Métodos de Ensino e Aprendizagem

\begin{tabular}{|c|c|c|c|c|c|c|c|}
\hline & Quan & tidade de & respost & $x$ Frequ & ência & & Percentual da \\
\hline ITEM & $A L$ & TA & MEDIA & & IXA & & frequênc \\
\hline $\begin{array}{l}\text { Recursos para preparação } \\
\text { das aulas }\end{array}$ & Sempre & $\begin{array}{l}\text { Quase } \\
\text { sempre }\end{array}$ & $\begin{array}{l}\text { Às } \\
\text { vezes }\end{array}$ & $\begin{array}{l}\text { Quase } \\
\text { nunca }\end{array}$ & Nunca & $\begin{array}{c}\mathrm{da} \\
\text { amostra }\end{array}$ & $\begin{array}{l}\text { total da } \\
\text { amostra }\end{array}$ \\
\hline
\end{tabular}




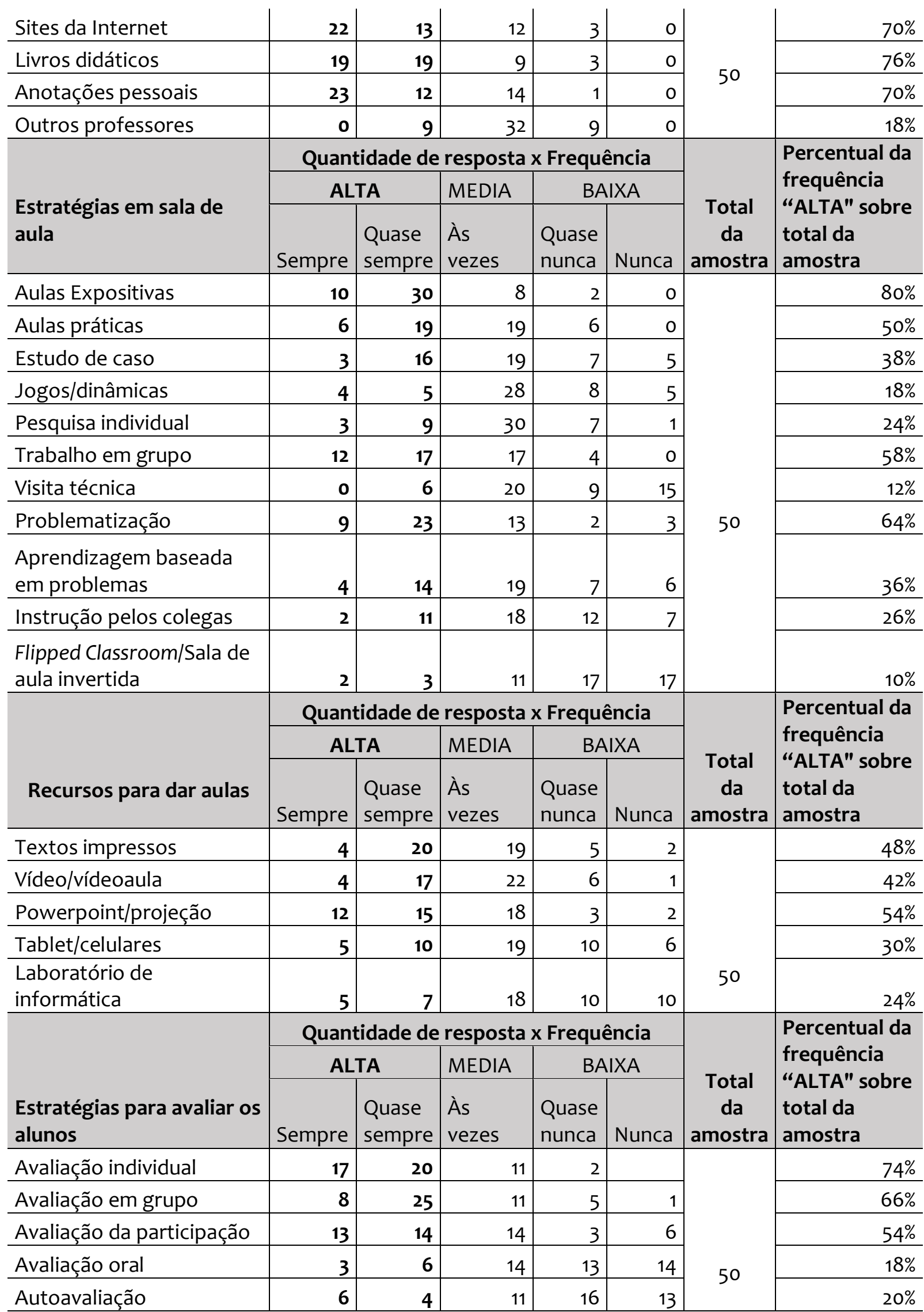

Fonte: Elaborado pela autora com base em Virgem (2016) 
Entre os recursos utilizados para a preparação das aulas, o "livro didático" despontou como o aderido com maior frequência pela maioria dos professores (76\%), seguido de "sites" e "anotações pessoais".

Entre as estratégias utilizadas em sala de aula, a que obteve alta adesão pela maioria dos professores (80\%) foi a da "aula expositiva", deixando evidente o quanto a prática ainda está pautada na transmissão, diferentemente do que apontaram as concepções docentes sobre o processo de ensino-aprendizagem que, em sua maioria, refletiam concepções ativas e dialógicas.

O "trabalho em grupo" adotado com alta frequência por 58\% dos docentes é uma importante ferramenta, que pode ser planejada para desenvolver as competências necessárias para a atuação profissional. Os grupos de trabalho podem funcionar como “equipes", de maneira que o estudante tome decisões e atue efetivamente de forma colaborativa, comprometendo-se com a aquisição do seu conhecimento e sendo capaz de compreender como o conhecimento construído será aplicado. O "estudo de caso" é uma técnica de metodologia ativa utilizada com frequência alta por 38\% dos docentes, porém outras metodologias ativas como "aprendizagem baseada em problemas, Instrução pelos colegas, sala de aula invertida" são menos utilizadas.

Observa-se que a alta aderência quanto à utilização do recurso “Powerpoint/projeção” (54\%), condiz com a estratégia mais utilizada de aula expositiva, já que normalmente o recurso de projeção é utilizado para substituir o quadro-negro e o giz. “Textos impressos" (48\%) e "vídeo/videoaula" (42\%) aparecem na sequência, tendo o laboratório de informática (24\%) encontrado baixa adesão dos professores.

Entre as estratégias para avaliar o aluno, a mais utilizada pela maioria dos participantes (74\%) é a avaliação individual. Na concepção tradicional de educação o professor transmite conhecimentos inquestionáveis; isso fomenta um tipo de avaliação da aprendizagem no qual se exige dos alunos apenas o que lhes foi transmitido, devendo demonstrar nas provas o quanto absorveu. $\mathrm{O}$ trabalho com metodologias ativas exige que o professor esteja mais próximo ao aluno, buscando feedback constante, avaliando o comportamento em equipe e incentivando a avaliação entre pares. Um ponto que esteve entre as mais baixas adesões (20\%), e que é importante para o amadurecimento e o senso de responsabilidade, é a autoavaliação, já que se espera que o aluno seja responsável pela construção do conhecimento. 
Tabela 3 - Frequência por prática docente - Utilização das Tecnologias

\begin{tabular}{|c|c|c|c|c|c|c|c|}
\hline \multirow{3}{*}{$\begin{array}{l}\text { Softwares de } \\
\text { tecnologias digitais de } \\
\text { informação e } \\
\text { comunicação (TDIC) }\end{array}$} & \multicolumn{5}{|c|}{ Quantidade de resposta x Frequência } & \multirow{3}{*}{$\begin{array}{c}\text { Total } \\
\text { da } \\
\text { amostra }\end{array}$} & \multirow{3}{*}{$\begin{array}{l}\text { Percentual da } \\
\text { frequência } \\
\text { "ALTA" sobre } \\
\text { total da } \\
\text { amostra }\end{array}$} \\
\hline & \multicolumn{2}{|c|}{ ALTA } & \multirow{2}{*}{$\begin{array}{l}\text { MEDIA } \\
\text { Às } \\
\text { vezes }\end{array}$} & \multicolumn{2}{|c|}{ BAIXA } & & \\
\hline & Sempre & $\begin{array}{l}\text { Quase } \\
\text { sempre }\end{array}$ & & $\begin{array}{l}\text { Quase } \\
\text { nunca }\end{array}$ & Nunca & & \\
\hline Redes sociais & 1 & 8 & 10 & 9 & 22 & \multirow{5}{*}{50} & $18 \%$ \\
\hline Aplicativos de jogos & 1 & 3 & 11 & 11 & 24 & & $8 \%$ \\
\hline Google Drive & 4 & 9 & 15 & 7 & 15 & & $26 \%$ \\
\hline $\begin{array}{l}\text { Aplicativos para criação } \\
\text { de mapa mental }\end{array}$ & 1 & 3 & 12 & 11 & 23 & & $8 \%$ \\
\hline Google groups & 0 & 5 & 12 & 11 & 22 & & $10 \%$ \\
\hline
\end{tabular}

Fonte: Elaborado pela autora

Pelos resultados da tabela 3 é possível notar a dificuldade de utilização de TDIC por parte dos docentes. Alguns citaram inclusive como desafio a "Dificuldade em mantê-los [os alunos] afastados do celular" e "fazê-los entender que o uso de celulares só é permitido em alguns momentos da aula". O Google Drive, software apontado como o utilizado com maior frequência pelos professores (26\%), é um repositório de material on-line que, apesar de poder ser utilizado para a produção colaborativa, na maioria das vezes é utilizado de forma tradicional, para a disponibilização de conteúdos.

Buscou-se avaliar também o conhecimento dos docentes a respeito de metodologias ativas fim de verificar se os participantes não conhecem - ou se conhecem, mas não sabem como utilizá-las-. Quando questionados se conheciam o termo "metodologias ativas de ensino-aprendizagem"; 92\% dos participantes respondeu afirmativamente e apenas $8 \%$ informou não possuir conhecimento sobre o termo. Quando se perguntou se na sua formação inicial ou continuada o tema metodologias ativas já havia sido abordado em algum curso, $38 \%$ disse que sim e $62 \%$ respondeu que não. Foi possível verificar desta forma que, embora a maioria dos participantes (92\%) conheça o termo, apenas $38 \%$ adquiriu esse conhecimento por meio de um curso, o que demonstra a relevância e o interesse dos docentes pela temática, mesmo aqueles que não fizeram estudo formal sobre o tema.

Solicitou-se ainda aos participantes que citassem 3 palavras ou expressões que lhes vinham à mente a respeito de "metodologias ativas de ensino-aprendizagem". Alguns 
responderam a essa pergunta dando exemplos de tipos de metodologias. A maioria das respostas foi assertiva, o que condiz como o percentual que afirmou conhecer o tema. Os participantes foram indagados também sobre qual seria a postura esperada do professor e do aluno em um trabalho com metodologias ativas e notou-se que a grande maioria possuía entendimento sobre as posturas esperadas deles, enquanto professores, e também dos alunos. Foi destacada entre as atitudes esperadas dos alunos a proatividade; salienta-se, porém que, para que esta atitude se concretize, é preciso que o professor adote metodologias em que os estudantes possam se envolver em atividades cada vez mais complexas, tendo que tomar decisões e avaliar os resultados.

A concepção de educação apoiada pela instituição pesquisada tem suas bases consolidadas nos preceitos da Educação Integral, que encontram alicerce na noção de formação humana integral. Acredita-se que os pressupostos de metodologia ativa vão ao encontro da formação humana integral, por isso buscou-se averiguar também qual conhecimento os docentes possuíam sobre essa dimensão.

Perguntou-se aos docentes se conheciam os pressupostos teóricos da "formação humana integral" e verificou-se que $56 \%$ não os conhecia e $44 \%$ sim. Solicitou-se ainda que citassem palavras ou expressões que Ihes viessem à cabeça a respeito da formação humana integral; tiveram destaque as respostas baixo: "Leva em conta a experiência prévia do aluno, sua vivência e interesses"; "Correlação, integração e consonância entre disciplinas técnicas e de caráter propedêutico"; "Cidadania, Trabalho, Pensamento Crítico"; "Trabalhar o aluno em sua integralidade, cognitivo, socioemocional".

As respostas demonstram expectativas que podem ser alcançadas com a utilização de metodologias ativas já que suas técnicas aproximam o aluno da criticidade, da autonomia, da afetividade e da contextualização. Acredita-se que o potencial destas metodologias seja ainda maior no ensino médio integrado à educação profissional, uma proposta que tem em seu cerne a perspectiva da Educação Integral.

\section{CONSIDERAÇÕES FINAIS}

A partir da análise dos resultados verificou-se que, embora a maioria das repostas sobre concepções de ensino e aprendizagem tenham se mostrado dialógicas e ativas, a análise das práticas docentes deixou claro que as atitudes, métodos, estratégias e recursos 
adotados em sala carregam um forte viés tradicionalista. Uma hipótese é que os docentes, sabendo previamente que esta se tratava de uma pesquisa acerca de metodologias ativas e formação integral, tenham procurado responder — mesmo sem a possibilidade de muita elaboração - de acordo com o tema da pesquisa e que, sua real concepção seja aquela que condiz com a prática, ainda que exista expectativa de mudança.

Foram destacados durante essa análise, desafios de diversa natureza, apontados pelos professores que, de alguma forma, pudessem impactar as suas práticas e desestimular a busca por inovações metodológicas. Entende-se que uma mudança de atitude muitas vezes depende de condições materiais diversas à vontade do docente, porém acredita-se que é possível ir modificando aos poucos o olhar, o pensamento, rumo a uma mudança efetivada através da ação. Os docentes demonstram expectativas que podem ser alcançadas com a utilização de metodologias ativas. Acredita-se que este potencial das metodologias ativas seja ainda maior se associado com o uso de metodologias ativas no ensino médio integrado à educação profissional, uma proposta que tem em seu cerne a perspectiva da formação integral. Na próxima etapa da pesquisa, pretende-se desenvolver, como contribuição técnica, um manual interativo para a utilização de metodologias ativas como produto educacional.

\section{REFERÊNCIAS}

ARAÚJO, Ronaldo Marcos de Lima; FRIGOTTO, Gaudêncio. Práticas pedagógicas e ensino integrado. Revista Educação em Questão, v. 52, n. 38, maio/ago. 2015. p. 61-80. Disponível em: https://periodicos.ufrn.br/educacaoemquestao/article/view/7956. Acesso em: 16 nov. 2019 .

BECKER, F. Aprendizagem - concepções contraditórias. Schème. v. 1, n. 1, jan./jul. 2008. p. 53-73.

CHRISTENSEN, Clayton; M. HORN, Michael B.; JOHNSON, Curtis W. Inovação na sala de aula: como a inovação de ruptura muda a forma de aprender. Porto Alegre: Bookman, 2009.

CUNHA, M. V. Democracia e educação: capítulos essenciais/John Dewey; apresentação e comentários Marcus Vinícius da Cunha. Tradução: Roberto Cavallari Filho. São Paulo: Ática, 2007. 136 p. (Ensaios comentados).

FREIRE, P. Pedagogia da autonomia: saberes necessários à prática educativa. 28. ed. São Paulo: Paz e Terra, 1996. 
FRIGOTTO, Gaudêncio. Concepções e mudanças no mundo do trabalho e o ensino médio. In: FRIGOTTO, Gaudêncio. et al. (orgs.) Ensino médio integrado: concepções e contradições. São Paulo: Cortez, 2012. cap. 2, p. 57-79.

GRABOWSKI, Gabriel; KUENZER, Acácia Zeneida. A produção do conhecimento no campo da educação profissional no regime de acumulação flexível. HOLOS, [S.I.], v. 6, p. 22-32, out. 2016. ISSN 1807-1600. Disponível em: http://www2.ifrn.edu.br/ojs/index.php/HOLOS/article/view/4983. Acesso em: 18 jun. 2019.

MORAN, J. Mudando a educação com metodologias ativas. SOUZA, C. A. de; MORALES, O. E. T. (org.). Convergências midiáticas, educação e cidadania: aproximações jovens. Ponta Grossa: UEPG; PROEX, 2015. (Coleção Mídias Contemporâneas). v. 2. p. 15-33. Disponível em: http://www2.eca.usp.br/moran/wp content/uploads/2013/12/mudando_moran.pdf. Acesso em: 15 nov. 2019.

MOURA, Dante Henrique; LIMA FILHO, Domingos Leite; SILVA, Mônica Ribeiro. Politecnia e formação integrada: confrontos conceituais, projetos políticos e contradições históricas da educação brasileira. Revista Brasileira de Educação, v. 20, n. 63, out.-dez. 2015. p. 10571080.

NOFFS, Neide Aquino; SANTOS, Sidnei da Silva. O desenvolvimento das metodologias ativas na educação básica e os paradigmas pedagógicos educacionais. Revista ECurriculum. (PUCSP) , v. 17, n. 4, out./dez. 2019 . Disponível em: https://dialnet.unirioja.es/servlet/articulo?codigo=7179260. Acesso em: 12 abr. 2020.

RAMOS, Marise. Possibilidades e desafios na organização do currículo integrado. In: FRIGOTTO, Gaudêncio et al. (orgs.) Ensino médio Integrado: concepções e contradições. São Paulo: Cortez, 2012. cap. 4, p. 107-127.

TEIXEIRA, Valquiria Oscar. Tecnologia e políticas educacionais: desafios e contribuições das tecnologias da informação e comunicação em escolas estaduais da cidade de Itaperuna. Texto Livre: linguagem e tecnologia, Belo Horizonte-MG, v. 9, n. 1, p. 140-159, 2016. Disponível em: http://periodicos.letras.ufmg.br/index.php/textolivre/article/view /10117/9622. Acesso em: 12 out. 2019.

VIRGEM, L.A.M. Aprendinsi: metodologia híbrida de ensino e aprendizagem baseada em problemas/projetos e escuta ativa para formação docente em educação profissional e tecnológica. 2016. Dissertação (Mestrado) - Universidade Federal da Bahia, Salvador, 2016. 